\title{
Application of Quality by Design Principles for Optimizing Process Variables of Extrusion and Spheronization of a Captopril Pellet Formulation
}

\author{
K. VEERUBHOTLAAND R. B. WALKER* \\ Division of Pharmaceutics, Faculty of Pharmacy, Chemical and Pharmaceutical Sciences Building, Rhodes University, \\ Grahamstown 6140, South Africa
}

\section{Veerubhotla and Walker: Application of Quality by Design Principles}

\begin{abstract}
Product development using quality by design is a proactive and risk-based approach that shifts the manufacturing process from empirical to science-based. Risk assessment was performed to identify and analyse risk areas for the manufacture of captopril pellets. Twelve experimental runs were performed using a Plackett-Burman screening design. Pareto plots revealed the effect of formulation and process variables on the responses monitored and facilitated the identification of the most critical parameters for optimization of the formulation. A response surface methodology approach in conjunction with a central composite design was used to optimize the Eudragit ${ }^{\circledR}$ RL $30 D(15-30 \mathrm{ml})$, microcrystalline cellulose (20$40 \% \mathrm{w} / \mathrm{w})$, sodium starch glycolate $(2-5 \% \mathrm{w} / \mathrm{w})$ and spheronizer speed (650-1050 rpm). The amount of Eudragit ${ }^{\circledR}$ RL 30D had a significant effect on \% yield, cumulative \% captopril released and content. The $\%$ cellulose had a moderate effect on particle size and \% yield. The signal to noise ratio was found to be adequate and therefore the model could be used to navigate the design space. The lower and upper limits for Eudragit ${ }^{\circledR}$ RL 30D, \% w/w cellulose, \% w/w disintegrant and spheronizer speed were established as 20-22 ml, 32-34 \% w/w, 3.7-4.1\% w/w, 928-1050 rpm, respectively. In vitro release of captopril from the optimized, lower and upper limit design space formulations ranged between 59.60-76.01, 95.68-110.34 and 101.12-111.84 \%, respectively. In conclusion, a risk-based quality by design approach and design of experiments was successfully used to establish a design space for captopril pellets manufactured by extrusion-spheronization while monitoring targeted outputs for safe and effective use.
\end{abstract}

Key words: Captopril, design of experiments, central composite design, extrusion-spheronisation, design space, response surface methodology

Any batch manufacturing process for production of a quality pharmaceutical product combines a number of unit operations. The impact of each individual operation on product attributes must be carefully considered during development as some operations may have a direct impact on the quality of the final product ${ }^{[1]}$. Routine practice entails changing one factor at one time, which is a time-consuming approach and often does not demonstrate the complete flexibility of a manufacturing process ${ }^{[2]}$.

The traditional approach used during product development is to use in-process and finished product testing to establish quality. If a material/batch does not meet predefined in-process/finished product specifications, which include but are not limited to percent purity, flowability and dissolution, the material

*Address for correspondence

E-mail: R.B.Walker@ru.ac.za

January-February 2020 or product is discarded ${ }^{[3]}$. This is expensive and endpoint examinations with limited flexibility provide incomplete scientific reasoning for batch failure. The acceptance of a final product is based on historical information for which the root cause of failure may not be fully understood ${ }^{[4]}$. Therefore, the main aim of applying $\mathrm{QbD}$ is to improve product quality through establishing the quality throughout a process rather than following the traditional approach of testing finished product to reflect quality.

This is an open access article distributed under the terms of the Creative Commons Attribution-NonCommercial-ShareAlike 3.0 License, which allows others to remix, tweak, and build upon the work non-commercially, as long as the author is credited and the new creations are licensed under the identical terms

Accepted 24 November 2019

Revised 06 September 2019 Received 12 July 2019 Indian J Pharm Sci 2020;82(1):76-87 
The importance of QbD is that efficient and effective investigation of variables of a process is undertaken and it facilitates an understanding of quality related issues permitting implementation of effective riskbased decisions so as to ensure consistency of quality throughout the lifecycle of a product. The use of structured risk management analysis may also facilitate effective quality decision making activities and enables implementation of appropriate risk mitigating actions. The knowledge gained from risk assessment analysis facilitates identification of important variables to be evaluated in the region of experimentation during screening experiments ${ }^{[5]}$. Statistical tools are widely used as part of product realization, including the design, development and improvement of existing processes, evaluation of material properties and optimization of manufacturing methods. The objective of screening studies is not to define an absolute numerical value for a specific factor but rather to establish whether the factor is significant and has an impact on processes or not ${ }^{[6]}$. Different statistical methods are used for screening/ optimization experiments and include factorial, Plackett-Burman design (PBD), D-optimal and Taguchi designs ${ }^{[7]}$. In this case the decision making activities related to the manufacture of captopril (CP) pellets using extrusion-spheronization process are evaluated.

The concept and use of design space (DS) has gained credibility and importance as a tool for the implementation of QbD. In the ICHQ8(R2) guideline $^{[8]}$ the DS is described as a multi-dimensional combination of independent variables that have been demonstrated to provide an assurance of quality. The objective of establishing a DS is to ensure consistent and reliable production of a product with quality during development, clinical trials and/or following commercialization $^{[9]}$. The use of DoE facilitates the study of the DS for a particular process and is used to establish a control strategy that can be continuously improved throughout the lifecycle of a product. DoE is a mathematical and statistical approach that has been used effectively during the development and optimization of processes. A full or fractional factorial, Central Composite (CCD), Box-Behnken or Doehlert design may be used for optimization and/or to estimate the optimal experimental conditions ${ }^{[10]}$.

The purpose of this manuscript was to describe the acquisition of sufficient process and product knowledge for the evaluation of potential risks related to the production of $\mathrm{CP}$ pellets manufactured using an extrusion and spheronization. An Ishikawa diagram was used as an initial risk assessment tool for the identification of potential risk factors for this product. A PBD screening study was undertaken following an assessment of the physiochemical characteristics of CP, formulation variables and process parameters that could impact the outcome of the proposed manufacturing approach. The critical factors identified and associated with formulation and process parameters were further optimized using a CCD DoE approach. Mathematical modelling was used to generate second-order quadratic equations to which the experimental data were best fitted and for the establishment of a DS. The DS for $\mathrm{CP}$ pellets in terms of material attributes and process parameters can be used to refine the limits for excipient composition and other critical characteristics so as to ensure product quality and assure that the product meets the targeted performance profile. To our knowledge, this manuscript is the first to demonstrate the proofof-concept for establishment of DS for CP pellets, produced by extrusion-spheronization.

\section{MATERIALS AND METHODS}

CP was donated by Protea Chemicals (Midrand, South Africa) and Avicel ${ }^{\circledR}$ PH103 (MCC) was donated by FMC (Philadelphia, PA, USA), Eudragit ${ }^{\circledR}$ RL 30 D (ERL) was donated by Rohm ${ }^{\circledR}$ Pharma (Darmstadt, Germany), sodium starch glycolate (SSG) and mannitol were donated by Aspen Pharmacare (Port Elizabeth, South Africa).

\section{Manufacture of CP pellets:}

Extrusion-spheronization is a multi-step process that involves the preparation of a wet mass or granulation, extrusion of that mass through a screen to form cylinders, size reduction of the cylinders using spheronization to form spheres followed by drying of the spherical shaped beads or pellets. Each batch manufactured was $50 \mathrm{~g}$ in size and was produced according to the experimental conditions determined using the experimental design as listed in Table 1 and the final yield of dried pellets was determined using an analytical balance.

\section{Risk assessment of manufacturing and material variables:}

The risks associated with process and product parameters for the manufacture of CP pellets were identified using a basic cause-and-effect or Ishikawa fishbone diagram. In the next stage of the process potential harm related to each identified factor or source of risk was estimated. The medium and high risk factors that may have an 
TABLE 1: PBD LISTING EXPERIMENTAL CONDITIONS USED AND RESPONSES MONITORED

\begin{tabular}{|c|c|c|c|c|c|c|c|c|c|c|c|c|c|c|c|}
\hline $\begin{array}{l}\text { Eudr- } \\
\text { agit } \\
\text { RL } \\
30 \mathrm{D} \\
\mathrm{x}_{1} \\
\mathrm{ml} \\
\end{array}$ & $\begin{array}{c}\text { MCC } \\
x_{2} \\
\% \\
w / w\end{array}$ & $\begin{array}{l}\text { SSG } \\
x_{3} \\
\% \\
w / w\end{array}$ & $\begin{array}{c}\text { Mixer } \\
\text { blade } \\
\mathbf{x}_{4} \\
\text { Type }\end{array}$ & $\begin{array}{c}\text { Dry } \\
\text { blen } \\
\text { ding } \\
x_{5} \\
\text { Speed }\end{array}$ & $\begin{array}{c}\text { Dry } \\
\text { blen } \\
\text { ding } \\
\text { time } \\
x_{6} \\
\text { sec } \\
\end{array}$ & $\begin{array}{c}\text { Extr } \\
\text { uder } \\
\text { speed } \\
\mathrm{x}_{7} \\
\mathrm{rpm}\end{array}$ & $\begin{array}{c}\text { Sphero- } \\
\text { nizer } \\
\text { speed } \\
\text { x }_{8} \\
\text { rpm }\end{array}$ & $\begin{array}{c}\text { Sphero- } \\
\text { nizer } \\
\text { time } \\
x_{9} \\
\text { sec }\end{array}$ & $\begin{array}{c}\text { Drying } \\
\text { time } \\
\mathrm{x}_{10} \\
\mathrm{hr}\end{array}$ & $\begin{array}{c}\text { Drying } \\
\text { tempe } \\
\text { rature } \\
\mathrm{x}_{0}\end{array}$ & $\begin{array}{c}\text { Yield } \\
\mathrm{y}_{1} \\
\%\end{array}$ & $\begin{array}{c}\text { Cumulative } \\
\% \mathrm{CP} \\
\text { released at } \\
0.5 \mathrm{~h} \mathrm{y}_{2}\end{array}$ & $\begin{array}{c}\text { CP } \\
\text { content } \\
y_{3} \\
\%\end{array}$ & $\begin{array}{c}\text { Angle of } \\
\text { repose } \\
y_{0}\end{array}$ & $\begin{array}{c}\text { Mean } \\
\text { particle } \\
\text { size } \\
\mathrm{y}_{5} \\
\mu \mathrm{m}\end{array}$ \\
\hline 15 & 40 & 5 & W & $\mathrm{H}$ & 300 & 35 & 650 & 30 & 4 & 60 & $8 \pm 1.95$ & 42 & .02 & .08 & 67 \\
\hline 5 & 20 & 2 & W & L & 60 & 25 & & 3 & 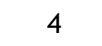 & 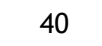 & $23 \pm 1.56$ & .23 & 01 & $5.7 \pm$ & \\
\hline 30 & 40 & 2 & W & L & 300 & 25 & 050 & 180 & 4 & 60 & $69.9 \pm 1.25$ & $50.0 \pm 5.22$ & $7.4 \pm 0.01$ & $22 \pm 0.17$ & $1207 \pm 3.27$ \\
\hline 30 & 40 & 2 & K & $\mathrm{H}$ & 300 & 25 & 650 & 30 & 8 & 40 & $54.8 \pm 2.00$ & $66.4 \pm 2.61$ & $63.2 \pm 0.06$ & $17.5 \pm 0.12$ & $1075 \pm 4.08$ \\
\hline 15 & 20 & 2 & K & L & 300 & 35 & & & & & & & & & \\
\hline 5 & 20 & 5 & W & $\mathrm{H}$ & 300 & 25 & 1050 & 180 & 8 & 40 & $4.5 \pm 0.95$ & 94.4 & $65 \pm 0.01$ & $10.16 \pm 0.18$ & $636 \pm 5.71$ \\
\hline 30 & 20 & 5 & $\mathrm{~K}$ & $\mathrm{H}$ & 60 & 25 & 650 & 180 & 4 & 60 & $42 \pm 1.89$ & $66.5 \pm 0.28$ & $87.7 \pm 0.02$ & $7.5 \pm 0.14$ & $5236 \pm 3.27$ \\
\hline 15 & 40 & 5 & K & $L$ & 60 & 25 & 50 & 30 & 8 & 60 & $29.3 \pm 1.51$ & & $96.8 \pm 0.05$ & $11.16 \pm 0.14$ & $581 \pm 2.04$ \\
\hline 30 & 20 & 2 & W & $\mathrm{H}$ & 60 & 35 & 1050 & 30 & 8 & 60 & $37.7 \pm 1.03$ & $34.2 \pm 4.18$ & $7.3 \pm 0.02$ & $40 \pm 0.12$ & $1698 \pm 1.67$ \\
\hline 30 & 40 & 5 & W & L & 60 & 35 & 650 & 180 & 8 & 40 & $70.9 \pm 2.29$ & $90.3 \pm 7.18$ & $85.6 \pm 0.03$ & $20.13 \pm 0.13$ & $1007 \pm 2.45$ \\
\hline 15 & 40 & 2 & K & $\mathrm{H}$ & 60 & 35 & 1050 & 180 & 4 & 40 & $12.5 \pm 0.72$ & $97.2 \pm 0.63$ & $90.4 \pm 0.08$ & $16.52 \pm 0.15$ & $838 \pm 4.17$ \\
\hline 30 & 20 & 5 & $\mathrm{~K}$ & $\mathrm{~L}$ & 300 & 35 & 1050 & 30 & 4 & 40 & $33.4 \pm 3.21$ & $92.7 \pm 0.61$ & $84.7 \pm 0.051$ & $16.3 \pm 0.07$ & $1346 \pm 4.50$ \\
\hline
\end{tabular}

Responses reported in $($ Mean $\pm S D)$

impact on a product or process were identified and screened using a PBD DoE ${ }^{[1]}$.

\section{Formulation development using PBD:}

In a PBD the experiments are conducted using combinations of high- and low-level values for input or process variables and were subsequently analysed for their impact or effect on the process. The efficiency in screening a large number of variables at the same time and testing for robustness allows for information about controlled factors that have a significant influence on the variability of processes to be identified. A PBD was generated and analysed using Design-Expert ${ }^{\circledR}$ software (version 8.0.4.1 Minneapolis, MN, USA). Eleven experiments were performed using independent formulation and process variables that included ERL, MCC \% w/w and SSG \% w/w levels, mixer blade shape ( $\mathrm{K}$ and whisk), dry blending speed and time, speed of extruder, spheronization speed and time, drying temperature and drying time at low (-1) and high $(+1)$ levels. All experiments were conducted in replicate $(n=3)$.

\section{Formulation optimization by CCD:}

Formulation variables such as the amount of ERL $\left(\mathrm{V}_{1}\right)$, $\% \mathrm{w} / \mathrm{w} \mathrm{MCC}\left(\mathrm{V}_{2}\right), \% \mathrm{w} / \mathrm{w} \mathrm{SSG}\left(\mathrm{V}_{3}\right)$ and a processing variable, spheronizer speed $\left(\mathrm{V}_{4}\right)$ were considered the main factors that required optimization to ensure that $\mathrm{CP}$ pellets, with adequate performance characteristics, were produced. With the aid of Design-Expert ${ }^{\circledR}$ software, a CCD of 30 experimental runs was generated using 4 factors at 5 levels, $-\alpha,+\alpha$, low (-1), medium (0) and high $(+1)$. Responses such as $\%$ yield $\left(\mathrm{R}_{1}\right)$, cumulative
$\%$ CP released at $0.5 \mathrm{~h}\left(\mathrm{R}_{2}\right), \mathrm{CP}$ content $\left(\mathrm{R}_{3}\right), \mathrm{AOR}\left(\mathrm{R}_{4}\right)$ and mean particle size (MPS; $\mathrm{R}_{5}$ ) were monitored.

\section{Angle of repose (AOR):}

An aliquot of each batch and powders (50-100 g) was poured into a funnel placed $3 \mathrm{~cm}$ above a horizontal surface. The material was permitted to flow from the funnel onto a horizontal surface under the force of gravity. The height of the resultant cone (h) and the radius of the base (r) were measured and the AOR calculated using Eqn. 1, Tan $\alpha=\mathrm{h} / \mathrm{r}$.

\section{Particle size distribution (PSD):}

Approximately $5 \mathrm{~g} \mathrm{CP}$ was accurately weighed and loaded onto pre-weighed sieves stacked in ascending order of mesh size. The basis of separation of particles is dependent on size and shape. The PSD was determined using sieve analysis (ASTM standard) with sieves ranging from 310 to $2000 \mu \mathrm{m}$ mesh size (Atechnik ${ }^{\circledR}$, Leinburg, Germany). The D50 was calculated by plotting a graph of \% weight of pellets retained versus pore size of the sieve.

\section{CP content:}

CP content was determined using a Waters ${ }^{\circledR}$ Alliance high performance liquid chromatography (HPLC) fitted with a PDA detector set at $210 \mathrm{~nm}$. Separation was achieved using a Phenomenox ${ }^{\circledR} 5 \mu \mathrm{m}$ Luna ${ }^{\circledR} \mathrm{C}_{18} 150 \times 4.6$ $\mathrm{mm}$ i.d. column and a mobile phase of acetonitrile and water in a $30: 70 \% \mathrm{v} / \mathrm{v}$ ratio at a flow rate of $1.0 \mathrm{ml} / \mathrm{min}$ with a column temperature of $24^{\circ}$. The $\mathrm{pH}$ of the buffer was adjusted to 3 using o-phosphoric acid. The CP pellets were crushed and powdered 
using a mortar and pestle. Approximately $100 \mathrm{mg}$ of powder was dissolved in mobile phase with sonication (Branson ${ }^{\circledR}$ B12 ultrasonic bath, Shelton, CN, USA) for $15 \mathrm{~min}$. The solution was then filtered using a $0.45 \mu \mathrm{m}$ HVLP filter membrane (Millipore ${ }^{\mathbb{B}}$, MA USA) prior to analysis using a validated HPLC method ${ }^{[12]}$.

\section{$\mathrm{CP}$ release from pellets:}

In vitro release of $\mathrm{CP}$ from the pellets was investigated using a VanKel $^{\circledR}$ Bio-Dis ${ }^{\circledR}$ dissolution apparatus (VanKel ${ }^{\circledR}$ Industries, NJ, USA) fitted with a model VK 750D (VanKel ${ }^{\circledR}$ Industries, New Jersey, USA) digitally controlled water circulation heater to maintain the temperature of the dissolution medium at $37^{\circ}$. Approximately $500 \mathrm{mg}$ CP pellets were accurately weighed and loaded into size 0 clear gelatin capsules (RoDis, Gauteng, South Africa). Dissolution studies were performed at 20 dips per min in $200 \mathrm{ml} 0.1 \mathrm{M}$ $\mathrm{HCl}(0.74 \mathrm{~g}$ of $\mathrm{KCl}$ and $0.54 \mathrm{ml}$ of $\mathrm{HCl}$ in $200 \mathrm{ml} \mathrm{HPLC}$ water) buffer at $\mathrm{pH} 1.6$ maintained at $37 \pm 0.5^{\circ}$. The inner tubes were fitted with $850 \mu \mathrm{m}$ (top) and $177 \mu \mathrm{m}$ (bottom) screens. Aliquots $(1.0 \mathrm{ml})$ of dissolution medium were withdrawn at 2, 5, 10, 15, 30, 45, 60 and $120 \mathrm{~min}$. The samples were analysed using a validated RP-HPLC method ${ }^{[12]}$.

\section{RESULTS AND DISCUSSION}

The identification of critical quality and other attributes affected by the manufacturing process and formulation composition was undertaken using risk assessment tools in accordance with the ICH Q9 guideline ${ }^{[13]}$. The attributes related to manufacture of the $\mathrm{CP}$ pellets were identified and an Ishikawa diagram developed (fig. 1). Based on sound science and process understanding, the major areas of risk likely to affect the product quality were identified. The main sources of product variability identified included raw material, equipment, unit operations such as wet granulation, extrusion, spheronization, drying temperature and time, in addition to the analytical methods used for product evaluation.

The first step of the extrusion-spheronization process is the preparation of a wet granulation mass. Different blades (K-shaped or Whisk blade) can be used to blend powders and distribute granulation and binder solutions. The physical properties of the materials, amount of binder and time of the granulation process can influence the particle size, hardness, sphericity and ultimately the rate of CP release from the pellets produced. The total output of the extrudate is governed by the extrusion speed that may in turn influence the size and surface properties of the finished product ${ }^{[14]}$.

The quality of pellets depended on the thickness and diameter of the aperture of the screen. In general, thick screens produce smooth and strongly bound extrudate whereas rough and loosely bound extrudate are formed from thin screens. The diameter of the perforations on the screen determines the size of pellets and larger

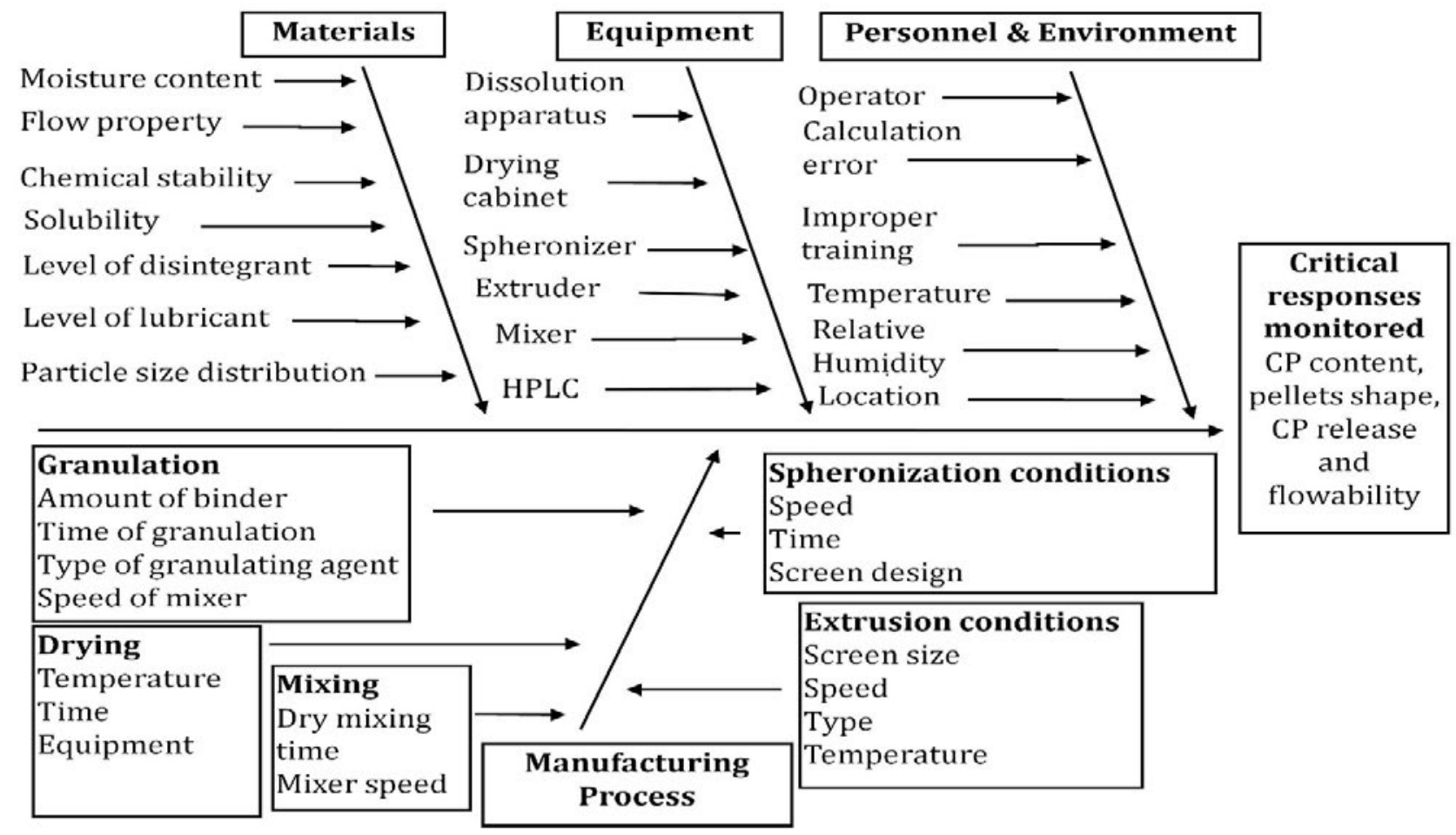

Fig. 1: Ishikawa diagram depicting the risk factors for the manufacture of $\mathrm{CP}$ pellets 
diameter pores produce large sized particles ${ }^{[15]}$. In view of this, a $1.0 \mathrm{~mm}$ diameter aperture screen was used throughout these studies. The speed of spheronization may affect the size of the pellets produced and an increase in the speed of spheronization resulted in an increase in the mean diameter of the particles produced. In the final step, the pellets were dried in an oven where extended drying times (4-6 h) and temperatures (40$60^{\circ}$ ) were necessary to remove all moisture from the pellets.

It has been reported that between $60-80 \%$ of product variability may be related to manufacturing and formulation-related criteria ${ }^{[16]}$. The impact on product quality due to low risk variables could be adjusted at other stages of manufacture whereas adequate control over the medium and high-risk variables required early investigation. Critical factors associated with formulation and processing such as amounts of ERL $\left(\mathrm{X}_{1}\right)$, MCC $\left(\mathrm{X}_{2}\right)$, SSG $\left(\mathrm{X}_{3}\right)$, mixer blade shape $\left(\mathrm{X}_{4}\right)$ (K- and Whisk-type), dry blending speed $\left(\mathrm{X}_{5}\right)$ (low, medium or high) and time $\left(\mathrm{X}_{6}\right)$, speed of extruder $\left(\mathrm{X}_{7}\right)$, spheronizer speed $\left(\mathrm{X}_{8}\right)$ and spheronization time $\left(\mathrm{X}_{9}\right)$, drying temperature $\left(\mathrm{X}_{10}\right)$ and time $\left(\mathrm{X}_{11}\right)$ were considered critical parameters that were evaluated experimentally using a PBD approach, as these were considered medium to high risk variables. Output responses such as \% yield $\left(\mathrm{Y}_{1}\right)$, cumulative \% $\mathrm{CP}$ released at $0.5 \mathrm{~h}$ $\left(\mathrm{Y}_{2}\right), \mathrm{CP}$ content $\left(\mathrm{Y}_{3}\right)$, AOR $\left(\mathrm{Y}_{4}\right)$ and MPS $\left(\mathrm{Y}_{5}\right)$ were monitored and the data are listed in Table 1.

Pareto plots were used to present the data for critical responses in a format in which the variables are ranked from the highest to lowest absolute value and the magnitude of each effect is represented by the height of the column for each variable. The AOR of the pellets ranged from $5.7^{\circ}$ to $40^{\circ}$, indicating that the pellets exhibited adequate flow properties. The MPS of pellets fell between 601 and $5236 \mu \mathrm{m}$. An increase in the amount of MCC in the formulation resulted in an increase in the MPS of the pellets as pellet porosity and PSD are influenced by the grade and particle size of the MCC used ${ }^{[17]}$. Pellets manufactured with MCC exhibit better flow and compressibility properties due to a larger particle size, low micro-pore volume and minimal surface roughness.

The outcome of ANOVA analysis revealed that the $\%$ yield, cumulative \% $\mathrm{CP}$ released at $0.5 \mathrm{~h}$ and $\mathrm{CP}$ content were significant with $\mathrm{p}$-values $<0.05$. The first-order linear Eqns. 2-6) derived for these responses are reported in terms of coded variables. A positive sign for the factors indicates an agonistic effect of that factor on a response whereas a negative sign reflects an antagonist effect on that response. Eqn. 2, $\mathrm{Y}_{1}=35.80+15.65 \mathrm{X}_{1}+7.07 \mathrm{X}_{2}-2.48 \mathrm{X}_{3}-1.83 \mathrm{X}_{4}-7.25 \mathrm{X}_{5}-$ $1.45 \mathrm{X}_{7}-4.59 \mathrm{X}_{8}+2.80 \mathrm{X}_{9}+2.37 \mathrm{X}_{10}+2.62 \mathrm{X}_{11}$; Eqn. 3, $\mathrm{Y}_{2}=80.49-26.97 \mathrm{X}_{1}-7.34 \mathrm{X}_{2}-15.24 \mathrm{X}_{4}-6.48 \mathrm{X}_{5}+4.82 \mathrm{X}_{6}-$ $6.52 \mathrm{X}_{7}+2.36 \mathrm{X}_{8}-6.76 \mathrm{X}_{9}-4.17 \mathrm{X}_{10}+0.792 \mathrm{X}_{11}$; Eqn. 4, $\mathrm{Y}_{3}=68.78-12.80 \mathrm{X}_{1}+3.22 \mathrm{X}_{2}+15.91 \mathrm{X}_{3}+17.33 \mathrm{X}_{-4}{ }^{-}$ $1.75 \mathrm{X}_{5}-1.65 \mathrm{X}_{6}+6.30 \mathrm{X}_{7}-10.18 \mathrm{X}_{8}+2.88 \mathrm{X}_{9}-$ $5.16 \mathrm{X}_{11} ; \quad$ Eqn. $5, \quad \mathrm{Y}_{4}=16.19+4.37 \mathrm{X}_{1}+0.84 \mathrm{X}_{2}-$ $2.86 \mathrm{X}_{3}-2.61 \mathrm{X}_{4}+1.59 \mathrm{X}_{5}+3.91 \mathrm{X}_{7}+3.14 \mathrm{X}_{8}-$ $1.42 \mathrm{X}_{9}+2.31 \mathrm{X}_{10}+1.82 \mathrm{X}_{11}$ Eqn. $6 ; \mathrm{Y}_{5}=1319.08+609.08 \mathrm{X}_{1}$ $-434.25 \mathrm{X}_{2}+346.08 \mathrm{X}_{4}+361.58 \mathrm{X}_{5}-355.75 \mathrm{X}_{6}-251.58 \mathrm{X}_{7}-$ $268.083 X_{8}+320.75 X_{9}-333.75 X_{10}+387.25 X_{11}$.

The sum of squares, model F-value, p-value and the regression coefficient $\left(\mathrm{R}^{2}\right)$ were used to assess model fit and are listed in Table 2. The value of $\mathrm{R}^{2}$ and standard deviation for the responses indicate the quality of the model. The value of $\mathrm{R}^{2}$ for most responses was close to unity, indicating a good correlation between the observed or experimental and predicted responses. Responses such as percent yield, cumulative $\% \mathrm{CP}$ released at $0.5 \mathrm{~h}$ and CP content revealed good correlation reliability between the adjusted $\mathrm{R}^{2}$ and predicted $\mathrm{R}^{2}$ values.

The Pareto plot depicted in fig. 2A revealed that a decrease in the volume of ERL from $30 \mathrm{ml}$ to $15 \mathrm{ml}$ resulted in a decrease in the yield of CP pellets. This observation may be attributed to the fact that during granulation the binder solution when sprayed onto powder materials results in adherence of the powders to the walls of the blender/mixer. In addition electrostatic forces between particles may also lead to adherence of materials to the vessel walls, resulting in a low yield. The speed of the spheronizer and spheronization time resulted in an increased loss of moisture from the extrudate and a loss of plasticity of the particles.

At high spheronizer speeds, the particles may also not round off into spheres and remain as dumbbell and/or long cylinder shaped extrudate, resulting in a decreased yield of usable pellets. Furthermore high speed

TABLE 2: SUMMARY OF STATISTICAL RESULTS FOR PBD STUDIES

\begin{tabular}{lccccc}
\hline Reponse & F-value & $\mathrm{P}$-value & $\mathbf{R}^{2}$ & Adj $\mathbf{R}^{2}$ & Pred $\mathbf{R}^{2}$ \\
\hline $\begin{array}{l}\% \text { yield } \\
\% \text { CP }\end{array}$ & 4003.48 & 0.0123 & 0.9999 & 0.9997 & 0.9964 \\
released & 261.40 & 0.0481 & 0.9996 & 0.9957 & 0.9449 \\
$\begin{array}{l}0.5 \mathrm{~h}^{*} \\
\% \mathrm{CP}\end{array}$ & & & & & \\
$\begin{array}{l}\text { content } \\
\text { AOR }\end{array}$ & 4058.74 & 0.0122 & 0.9999 & 0.9972 & 0.9964 \\
MPS & 19.77 & 0.1734 & 0.9949 & 0.9446 & 0.2755 \\
\hline
\end{tabular}

*Signifcant responses 
spheronization is likely to result in the production of fines that may be lost between the spheronizer plate and inner wall of the spheronizing vessel, contributing to a low final yield. Based on the experimental results the amount of MCC in the formulation was found to increase the yield of pellets proportionally. This may be due to the ability of MCC to adsorb and retain large quantities of water whilst retaining high internal porosity and improved plasticity of wet masses thereby enhancing the outcome of the spheronization process resulting in higher yields ${ }^{[18]}$.

The Pareto plot depicted in fig. 2B reveals that variables such as drying and mixing times have an antagonistic effect on the cumulative \% CP released at $0.5 \mathrm{~h}$. This effect can be explained due to decreased dissolution of
$\mathrm{CP}$ from pellets as a consequence of reduced porosity within the pellet that retards entry of the dissolution medium into the core of the pellet ${ }^{[19]}$. The data in the Pareto plot suggests that an increase in the volume of ERL used, results in a significant decrease in the cumulative \% $\mathrm{CP}$ released at $0.5 \mathrm{~h}$. In addition the use of ERL may result in the formation of a matrix in the core that on increasing the amount of liquid used, results in the manufacture of dense, hard pellets that exhibit slow release.

ERL is hydrophilic and more permeable than other polymethacrylate-based copolymers due to the presence of quaternary ammonium functional groups in the molecular structure ${ }^{[20]}$. The interaction of chloride counter ions within the quaternary ammonium functional
A

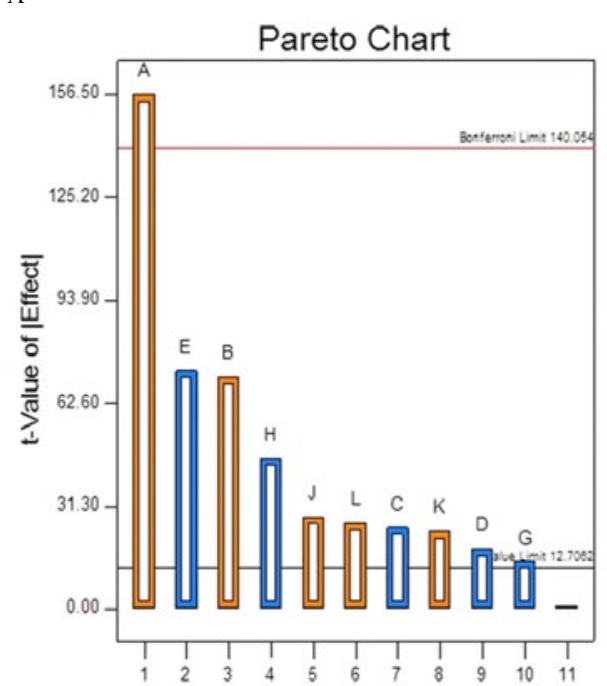

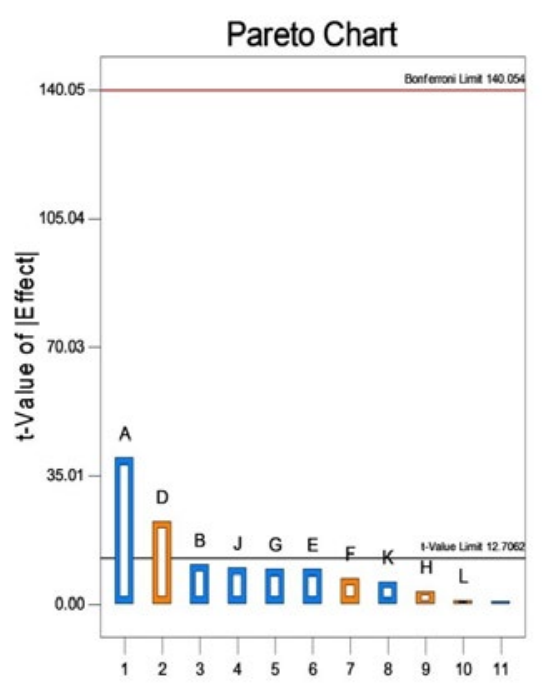

B

Rank

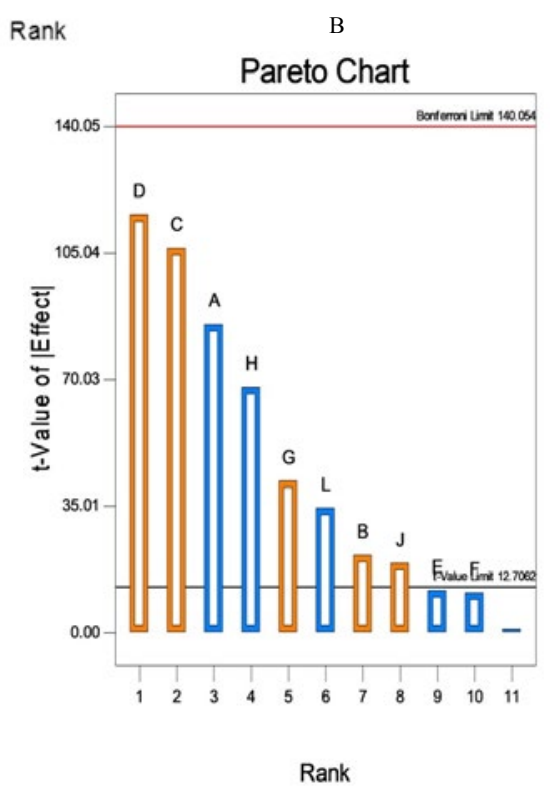

Fig. 2: Pareto plots for cumulative (A) percent field, (B) \% CP released at $0.5 \mathrm{~h},(\mathrm{C}) \% \mathrm{CP}$ content A: Eudragit RS 30D, B: MCC, C: SSG, D: mixer blade, E: mixer speed, F: mixing time, G: extruder, H: spheronizer speed, K: drying time, $L$ : drying temperature, $(\square)$ positive effects, $(\square)$ negative effects 
groups with anionic buffer species in the dissolution medium may influence the degree of hydration and swelling of the polymer, thereby affecting the release of CP. In this case, the antagonistic effect observed with respect to $\mathrm{CP}$ release may be driven by the chloride salt form of the polymer due to the lack of anions to replace the chloride ions at low buffer strength, therefore limiting CP release.

The Pareto plot depicted in fig. $2 \mathrm{C}$ revealed that input variables such as mixer blade type, amount of SSG and MCC used, extruder speed and spheronization time had a direct impact on CP content. The use of different blade types, altered powder flow during mixing and might result in changes in the loading capacity for $\mathrm{CP}$. The mixer blades used, differed in design, geometry and curvature on the bottom surface of the blade. The length of curvature of the K-blade was $8.65 \mathrm{~cm}$ and that of the whisk blade $6.8 \mathrm{~cm}$ clearly indicating that efficient mixing of powders is more likely with a K-blade, as it is capable of ensuring a greater area of contact with powders than the whisk blade. The formulations manufactured using the whisk blade exhibited a CP content ranging between 7.3-88.6\% and those manufactured using the K-blade exhibited CP content between 63.2 and $96.8 \%$. Therefore more efficient mixing using the K-blade resulted in a more homogenous distribution of $\mathrm{CP}$ and this blade was consequently used for all future studies. An increase in the extruder speed resulted in greater roughness and the presence of greater surface disruption of the extrudate, resulting in poor quality of pellets that eventually led to the production of excessive fines and a wider particlesize distribution, in addition to a low yield and poor content uniformity.

Following an extensive study of formulation and process variables, parameters such as the amount of ERL $\left(\mathrm{V}_{1}\right), \% \mathrm{w} / \mathrm{w} \operatorname{MCC}\left(\mathrm{V}_{2}\right), \% \mathrm{w} / \mathrm{w} \mathrm{SSG}\left(\mathrm{V}_{3}\right)$ and the processing variable spheronizer speed $\left(\mathrm{V}_{4}\right)$ were

\section{TABLE 3 CCD EXPERIMENTS GENERATED FOR CP OPTIMIZATION}

\begin{tabular}{|c|c|c|c|c|c|c|c|c|c|}
\hline Run & $\begin{array}{c}\text { Eudragit } \\
\text { RL30D (ml) }\end{array}$ & $\begin{array}{c}\text { MCC } \\
(\% \mathrm{w} / \mathrm{w})\end{array}$ & $\begin{array}{c}\text { SSG } \\
(\% w / w)\end{array}$ & $\begin{array}{l}\text { Spheronizer } \\
\text { speed (rpm) }\end{array}$ & Yield (\%) & $\begin{array}{c}\text { \% CP released } \\
\text { at } 0.5 \mathrm{~h}\end{array}$ & $\begin{array}{c}\text { CP content } \\
(\%)\end{array}$ & AOR $\left({ }^{\circ}\right)$ & MPS $(\mu \mathrm{m})$ \\
\hline & $v_{1}$ & $\mathrm{~V}_{2}$ & $\mathrm{~V}_{3}$ & $V_{4}$ & $Y_{1}$ & $Y_{2}$ & $Y_{3}$ & $Y_{4}$ & $Y_{5}$ \\
\hline 1 & 15 & 20 & 2 & 650 & $16.54 \pm 0.04$ & $56.2 \pm 0.64$ & $49.8 \pm 0.22$ & $40 \pm 0.01$ & $849.5 \pm 0.41$ \\
\hline 2 & 15 & 20 & 5 & 1050 & $33.14 \pm 0.01$ & $85.8 \pm 0.57$ & $58 \pm 0.05$ & $40 \pm 0.64$ & $789 \pm 0.37$ \\
\hline 3 & 15 & 40 & 2 & 1050 & $29.46 \pm 0.02$ & $87.3 \pm 1.43$ & $64.2 \pm 0.03$ & $10.59 \pm 0.05$ & $575 \pm 0.01$ \\
\hline 4 & 22.5 & 30 & 3.5 & 850 & $63.2 \pm 0.07$ & $82.9 \pm 1.96$ & $33.5 \pm 0.02$ & $4.01 \pm 0.01$ & $1875.5 \pm 0.43$ \\
\hline 5 & 15 & 40 & 5 & 1050 & $40.18 \pm 0.01$ & $84.9 \pm 0.27$ & $49.1 \pm 0.04$ & $6.1 \pm 0.06$ & $752.6 \pm 5.96$ \\
\hline 6 & 30 & 40 & 5 & 1050 & $79.62 \pm 0.01$ & $6.4 \pm 0.92$ & $18.1 \pm 0.01$ & $10.97 \pm 0.05$ & $1653.8 \pm 0.25$ \\
\hline 7 & 22.5 & 10 & 3.5 & 850 & $42.22 \pm 0.09$ & $88.7 \pm 3.35$ & $36 \pm 0.017$ & $9.97 \pm 0.04$ & $3138.1 \pm 0.05$ \\
\hline 8 & 22.5 & 30 & 3.5 & 850 & $78.62 \pm 0.07$ & $94 \pm 2.6$ & $35.7 \pm 0.27$ & $4.43 \pm 0.2$ & $1827.3 \pm 0.01$ \\
\hline 9 & 22.5 & 30 & 3.5 & 850 & $86.88 \pm 0.11$ & $91.4 \pm 1.37$ & $37.7 \pm 0.1$ & $16.98 \pm 0.02$ & $1829.6 \pm 0.78$ \\
\hline 10 & 22.5 & 30 & 3.5 & 850 & $63.06 \pm 0.05$ & $67.4 \pm 0.20$ & $41.4 \pm 0.01$ & $12.12 \pm 0.01$ & $1168.5 \pm 0.04$ \\
\hline 11 & 7.5 & 30 & 3.5 & 850 & $3.1 \pm 0.02$ & $108.6 \pm 5.4$ & $42.9 \pm 0.05$ & $40 \pm 0.01$ & $557 \pm 1.63$ \\
\hline 12 & 22.5 & 30 & 3.5 & 850 & $70.12 \pm 0.79$ & $71.8 \pm 0.56$ & $38.8 \pm 0.14$ & $4.93 \pm 0.06$ & $1821.3 \pm 1.15$ \\
\hline 13 & 30 & 20 & 5 & 1050 & $51.5 \pm 0.14$ & $43.4 \pm 3.94$ & $11 \pm 0.02$ & $5.85 \pm 0.01$ & $2805.8 \pm 0.94$ \\
\hline 14 & 22.5 & 30 & 3.5 & 450 & $69.52 \pm 0.04$ & $84.7 \pm 0.16$ & $34.8 \pm 0.01$ & $10.68 \pm 0.09$ & $1058.7 \pm 0.05$ \\
\hline 15 & 22.5 & 30 & 3.5 & 1250 & $68.4 \pm 0.03$ & $98.8 \pm 5.19$ & $38.2 \pm 0.02$ & $12.47 \pm 0.02$ & $935.4 \pm 0.56$ \\
\hline 16 & 15 & 40 & 5 & 650 & $29.32 \pm 0.06$ & $85.2 \pm 7.62$ & $58.7 \pm 0.7$ & $3.66 \pm 0.05$ & $990 \pm 1.64$ \\
\hline 17 & 30 & 40 & 2 & 1050 & $60.1 \pm 0.06$ & $54.1 \pm 1.76$ & $18.1 \pm 0.54$ & $7.73 \pm 0.82$ & $1806.9 \pm 5.96$ \\
\hline 18 & 22.5 & 30 & 6.5 & 850 & $52.1 \pm 0.05$ & $87.2 \pm 0.19$ & $33.9 \pm 0.04$ & $10.68 \pm 0.01$ & $894.8 \pm 2.86$ \\
\hline 19 & 30 & 40 & 5 & 650 & $82.84 \pm 0.01$ & $42.3 \pm 0.59$ & $23.4 \pm 0.08$ & $7.96 \pm 0.05$ & $1166.3 \pm 0.74$ \\
\hline 20 & 22.5 & 50 & 3.5 & 850 & $58.9 \pm 0.03$ & $88.6 \pm 1.01$ & $30.9 \pm 0.07$ & $14.14 \pm 0.02$ & $558.2 \pm 1.63$ \\
\hline 21 & 30 & 20 & 2 & 1050 & $29.5 \pm 0.49$ & $48.2 \pm 0.59$ & $14.3 \pm 0.18$ & $8.85 \pm 0.73$ & $4075 \pm 0.83$ \\
\hline 22 & 15 & 40 & 2 & 650 & $42.18 \pm 0.05$ & $66.3 \pm 1.81$ & $37.1 \pm 0.21$ & $20.98 \pm 0.03$ & $781.8 \pm 0.1$ \\
\hline 23 & 15 & 20 & 5 & 650 & $43.9 \pm 0.21$ & $63.3 \pm 6.32$ & $29.8 \pm 0.26$ & $29.99 \pm 0.3$ & $1020.1 \pm 0.14$ \\
\hline 24 & 22.5 & 30 & 3.5 & 850 & $61.74 \pm 0.3$ & $101.4 \pm 4.5$ & $36.2 \pm 0.6$ & $8.08 \pm 0.6$ & $1829.2 \pm 0.70$ \\
\hline 25 & 22.5 & 30 & 0.5 & 850 & $65 \pm 0.6$ & $70.2 \pm 8.48$ & $27.1 \pm 0.94$ & $8.46 \pm 0.3$ & $1060.8 \pm 0.40$ \\
\hline 26 & 30 & 20 & 5 & 650 & $38.96 \pm 0.6$ & $21.8 \pm 1.40$ & $4.6 \pm 0.94$ & $8.53 \pm 0.04$ & $3771.7 \pm 0.47$ \\
\hline 27 & 15 & 20 & 2 & 1050 & $42.1 \pm 0.12$ & $89.4 \pm 19$ & $69.1 \pm 0.14$ & $40 \pm 0.01$ & $941.1 \pm 0.39$ \\
\hline 28 & 37.5 & 30 & 3.5 & 850 & $32.14 \pm 0.12$ & $36.2 \pm 0.97$ & $13.5 \pm 0.1$ & $40 \pm 0.03$ & $4388 \pm 0.38$ \\
\hline 29 & 30 & 40 & 2 & 650 & $72.2 \pm 0.4$ & $19 \pm 0.97$ & $5 \pm 0.5$ & $5.85 \pm 0.08$ & $849.5 \pm 0.7$ \\
\hline 30 & 30 & 20 & 2 & 650 & $40.36 \pm 0.1$ & $36.2 \pm 4.7$ & $13.5 \pm 0.08$ & $40 \pm 0.4$ & $4388 \pm 1.24$ \\
\hline
\end{tabular}


considered as critical factors that required further optimization, to ensure that $\mathrm{CP}$ pellets with adequate performance characteristics were produced. The CCD design required 30 experimental runs and the corresponding responses for each run are summarized in Table 3.

\section{TABLE 4: SUMMARY OF STATISTICAL RESULTS} FOR CCD STUDIES

\begin{tabular}{lccccc}
\hline Response & F-value & P-value & $\mathbf{R}^{2}$ & Adj $\mathbf{R}^{2}$ & Pred $\mathbf{R}^{2}$ \\
\hline $\begin{array}{l}\text { \% yield* } \\
\text { \% CP }\end{array}$ & 8.400 & $<0.0001$ & 0.8869 & 0.7813 & 0.4461 \\
$\begin{array}{l}\text { released } \\
0.5 \mathrm{~h}^{*}\end{array}$ & 2.607 & 0.0379 & 0.7088 & 0.4369 & -0.4945 \\
$\%$ CP & & & & & \\
content* $^{*}$ & 5.395 & 0.0012 & 0.8343 & 0.6796 & 0.0604 \\
AOR $^{*}$ & 2.746 & 0.0309 & 0.7193 & 0.4574 & -0.5018 \\
MPS $^{*}$ & 31.255 & $<0.001$ & 0.9668 & 0.9359 & 0.8496 \\
\hline
\end{tabular}

*Signifcant responses
The quadratic mathematical Eqns derived to establish relationship(s) between input variables and the responses monitored are mathematically represented in Eqns. 7-11. The ANOVA results for CCD experiments are summarized in Table 4.

The percent yield $\left(\mathrm{R}_{1}\right)$, cumulative $\% \mathrm{CP}$ released at $0.5 \mathrm{~h}\left(\mathrm{R}_{2}\right)$, CP content $\left(\mathrm{R}_{3}\right)$, AOR $\left(\mathrm{R}_{4}\right)$ and MPS $\left(\mathrm{R}_{5}\right)$ were found to be significant parameters based on $p$-value $<0.05$. The negative value for the predicted $\mathrm{R}^{2}$ value indicated that the model is not suitable for predicting responses $\mathrm{R}_{2}$ and $\mathrm{R}_{5}$ and therefore required further refinement. Adequate precision, a measure of the signal-to-noise ratio, was 19.24, indicating that an adequate signal had been generated and that these data can be used to navigate the DS for this set of variables. Eqn. 7, $\mathrm{R}_{1}=8.385+0.862 \mathrm{~V}_{1}+0.507 \mathrm{~V}_{2}+0.140 \mathrm{~V}_{3}+0.015$ $\mathrm{V}_{4}+0.520 \quad \mathrm{~V}_{1} \quad \mathrm{~V}_{2}+0.109 \quad \mathrm{~V}_{1} \quad \mathrm{~V}_{3}-0.145 \quad \mathrm{~V}_{1} \mathrm{~V}_{4}-0.116$ $\begin{array}{lllllll}\mathrm{V}_{2} & \mathrm{~V}_{3}-0.164 & \mathrm{~V}_{2} & \mathrm{~V}_{4}+0.070 & \mathrm{~V}_{3} & \mathrm{~V}_{4}-1.177 & \mathrm{~V}_{1}{ }^{2}-0.334\end{array}$
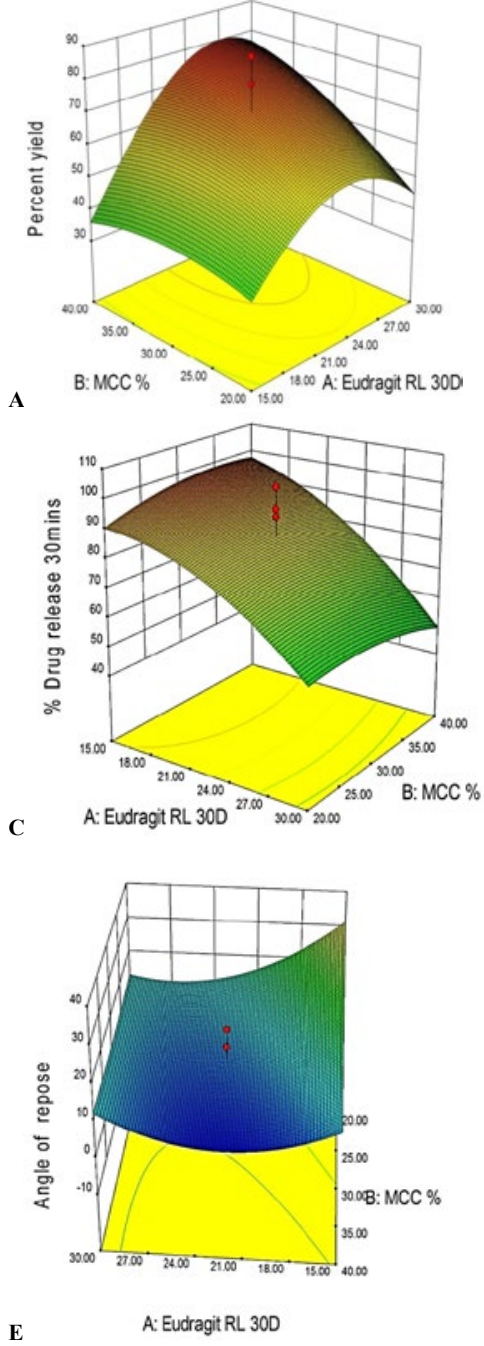

B
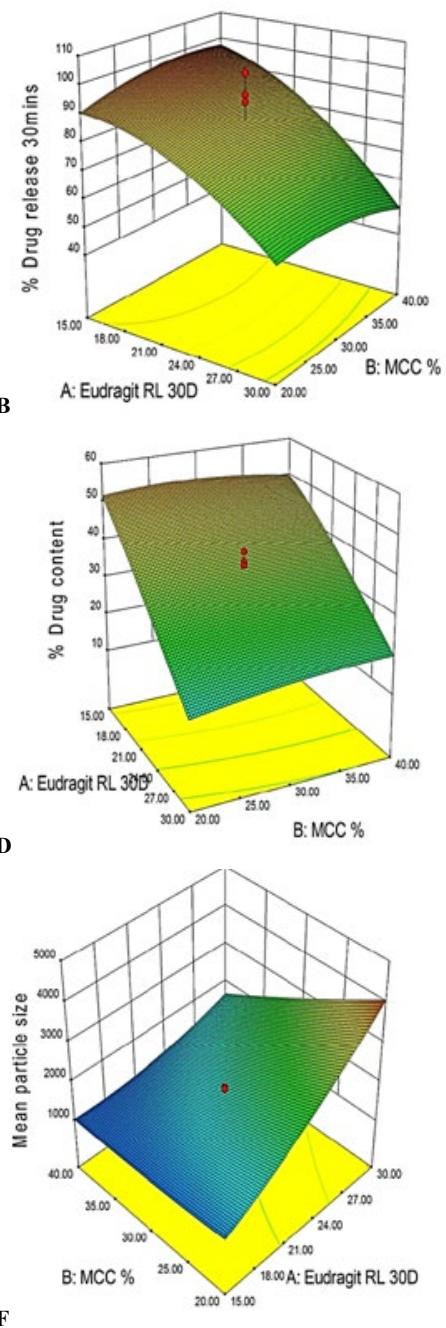

Fig. 3: 3D response surface plot

(A) Eudragit ${ }^{\circledR}$ RL 30D and \% MCC content on \% yield; (B and C) Eudragit ${ }^{\circledR}$ RL 30D and \% MCC content on cumulative \% CP released at $0.5 \mathrm{~h}$; (D) Eudragit ${ }^{\circledR}$ RL 30D and \% MCC on CP content (\%); (E) Eudragit ${ }^{\circledR}$ RL 30D and \% MCC content on the angle of repose 
$\mathrm{V}_{2}{ }^{2}-0.195 \mathrm{~V}_{3}{ }^{2}-0.029 \mathrm{~V}_{4}^{2}$; Eqn. 8, $\mathrm{R}_{2}=84.817-20.492$ $\mathrm{V}_{1}+0.042 \quad \mathrm{~V}_{2}+0.433 \quad \mathrm{~V}_{3}+5.725 \quad \mathrm{~V}_{4}-3.55 \quad \mathrm{~V}_{1} \mathrm{~V}_{2}-3.975$ $\mathrm{V}_{1} \mathrm{~V}_{3}-2.725 \mathrm{~V}_{1} \mathrm{~V}_{4}+0.487 \mathrm{~V}_{2} \mathrm{~V}_{3}-4.337 \mathrm{~V}_{2} \mathrm{~V}_{4}-5.837$ $\mathrm{V}_{3} \mathrm{~V}_{4}-7.648 \mathrm{~V}_{1}^{2}-3.585 \mathrm{~V}_{2}^{2}-6.073 \mathrm{~V}_{3}^{2}-2.810 \mathrm{~V}_{4}^{2}$; Eqn. $9, \mathrm{R}_{3}=6.097-1.436 \quad \mathrm{~V}_{1}+0.088 \mathrm{~V}_{2}+0.004 \quad \mathrm{~V}_{3}+0.331$ $\begin{array}{lllllll}\mathrm{V}_{4}+0.146 & \mathrm{~V}_{1} & \mathrm{~V}_{2}+0.146 & \mathrm{~V}_{1} & \mathrm{~V}_{3}-0.123 & \mathrm{~V}_{1} & \mathrm{~V}_{4}+0.465\end{array}$ $\begin{array}{lllllll}\mathrm{V}_{2} & \mathrm{~V}_{3}-0.124 & \mathrm{~V}_{2} & \mathrm{~V}_{4}-0.201 & \mathrm{~V}_{3} & \mathrm{~V}_{4}-0.289 & \mathrm{~V}_{1}{ }^{2}-0.122\end{array}$ $\mathrm{V}_{2}^{2}-0.188 \mathrm{~V}_{3}^{2}-0.057 \mathrm{~V}_{4}^{2}$; Eqn. $10, \mathrm{R}_{4}=8.425-3.982$ $\mathrm{V}_{1}-5.46 \mathrm{~V}_{2}-2.354 \mathrm{~V}_{3}-0.971 \mathrm{~V}_{4}+4.871 \mathrm{~V}_{1} \mathrm{~V}_{2}+0.168 \mathrm{~V}_{1}$ $\mathrm{V}_{3}-1.937 \mathrm{~V}_{1} \mathrm{~V}_{4}+1.751 \mathrm{~V}_{2} \mathrm{~V}_{3}+1.297 \mathrm{~V}_{2} \mathrm{~V}_{4}+3.277 \mathrm{~V}_{3}$ $\mathrm{V}_{4}+7.834 \mathrm{~V}_{1}^{2}+0.848 \mathrm{~V}_{2}^{2}+0.226 \mathrm{~V}_{3}^{2}+0.728 \mathrm{~V}_{4}^{2}$; Eqn. $11, \mathrm{R}_{5}=1725.233+894.996 \mathrm{~V}_{1}-634.338 \mathrm{~V}_{2}-68.729$ $\mathrm{V}_{3}-27.679 \mathrm{~V}_{4}-566.481 \mathrm{~V}_{1} \mathrm{~V}_{2}-132.881 \mathrm{~V}_{1} \mathrm{~V}_{3}+46.856$ $\begin{array}{lllllll}\mathrm{V}_{1} & \mathrm{~V}_{4}+151.031 & \mathrm{~V}_{2} & \mathrm{~V}_{3}+151.193 & \mathrm{~V}_{2} & \mathrm{~V}_{4}-92.256 & \mathrm{~V}_{3}\end{array}$ $\mathrm{V}_{4}+208.005 \mathrm{~V}_{1}^{2}+51.918 \mathrm{~V}_{2}^{2}-165.67 \mathrm{~V}_{3}^{2}-160.857 \mathrm{~V}_{4}^{2}$.

The 3D response surface plot for yield of CP pellets as impacted by ERL and \% w/w MCC content is depicted in fig. 3A. An increase in the amount of ERL from 15 to $30 \mathrm{ml}$ resulted in a significant increase in yield of CP pellets from 16.54 to $79.62 \%$. The increase in the level of MCC in the formulation from 20 to $40 \% \mathrm{w} / \mathrm{w}$ resulted in a significant increase in yield of CP pellets from 16.52 to $42.18 \%$.

The combined effect of the levels of these excipients had a significant impact on the overall percent yield and increasing the level of ERL and \% w/w MCC to high levels resulted in theyield increasing from 43.9 to $82.84 \%$ when the $\% \mathrm{w} / \mathrm{w}$ SSG and spheronizer speed were constant. The reason for the synergistic effect might be the ability of MCC to adsorb and retain large volumes of water or, in this case, the increased quantity of granulation fluid that might enhance the cohesiveness of powders that impart appropriate rheological properties to the wet mass, which would in turn, produce sufficient extrudate of adequate quality to result in an increased yield of pellets ${ }^{[21]}$.

A 3D response surface plot for the impact of ERL and $\%$ MCC content on the cumulative \% CP released at $0.5 \mathrm{~h}$ suggests that ERL had an antagonistic effect on the $\% \mathrm{CP}$ released, when the $\% \mathrm{w} / \mathrm{w}$ MCC was kept constant (figs. 3B and C). The amount of MCC and SSG have an agonistic effect on \% $\mathrm{CP}$ released. The reason for such behavior could be the addition of the SSG that is a super disintegrant, which might have created pores/ channel in the pellets, essentially making formulation porous and facilitating immediate release of $\mathrm{CP}$ from the formulation despite the pellets remaining intact in the dissolution medium, unlike conventional IR dosage forms because of the insoluble nature of polymer use of Eudragit and $\mathrm{MCC}^{[22]}$. The influence of the amount of granulation liquid on $\mathrm{CP}$ released could be due to the hardness, density and the structure of pellets formed, with this granulating fluid ${ }^{[23]}$.

The 3D response surface plot depicted in fig. 3D suggested that an increase in the amount of ERL in the formulation resulted in a significant decrease in the CP content, from approximately 49 to $13.5 \%$. The MCC content, amount of SSG and spheronizer speed do not appear to have a significant effect on content with all $p$-value $>0.05$. The negative effect of the amount of granulation liquid on CP loading capacity may be a consequence of the manner in which the granulation fluid is sprayed onto and dispersed in the powder blend in which the surfaces of MCC particles adsorb readily and with rapid formation of granules with low $\mathrm{CP}$ entrapment ${ }^{[24]}$. In addition, the use of a planetary mixer required the operator to scrape material from the edges of the bowl during granulation, which may have impacted the distribution of $\mathrm{CP}$ due to the timing of granulation fluid addition ${ }^{[25]}$.

The amount of ERL, \% w/w SSG and the spheronizer speed had a negative effect on the flow properties of pellets. An increase in the amount of MCC from 20 to $40 \% \mathrm{w} / \mathrm{w}$ resulted in a decrease in the AOR from 40 to $10.59^{\circ}$, which is indicative of excellent flow properties of the pellets. The $3 \mathrm{D}$ response surface plot constructed is depicted in fig. 3E. The change in $\% \mathrm{w} / \mathrm{w} \mathrm{MCC}$ content and spheronizer speeds from high to low levels at constant ERL and \% w/w SSG content resulted in a high value for the AOR of $40^{\circ}$, suggesting the potential for poor flow. The good flow properties observed are a result of the granular nature of the formulations, which is enhanced by the increased amount of $\mathrm{MCC}^{[26]}$. The CCD-CP batches 1, 2, 11, 27, 28 and 30 suggested poor flow was possible as the AOR for these batches was $>40$. The pellets formed for these batches were irregular in shape and adhered to each other resulting in poor flow. The 3D response surface plot revealed that a change in $\% \mathrm{w} / \mathrm{w}$ MCC content and spheronizer speed from high to low levels when the ERL and \% w/w SSG content were constant resulted in high AOR values of approximately $40^{\circ}$ suggesting poor flow properties would be evident.

The 3D response surface plot of the effect of ERL and $\% \mathrm{w} / \mathrm{w}$ MCC content on particle size is depicted in fig. 3F. The plot revealed that the amount of ERL used was directly proportional to the particle size of the pellets and an increase in the volume from 15 to $30 \mathrm{ml}$ resulted in an increase in particle size from 575 to 
$1806.9 \mu \mathrm{m}$. The agonist action of ERL may be explained by the fact that the particle size of the excipients in the powder blend is small, which offers a relatively large surface area and therefore requires additional binder solution to achieve the desired sphericity ${ }^{[27]}$. As the $\%$ w/w MCC used was increased from 20 to $40 \%$ w/w, the particle size of the pellets decreased from 941.1 to 575 $\mu \mathrm{m}$, which may be the result of better adhesion between particles due to reduced inter particulate distances and forces and stronger bonds increasing the packing density of the particles.

The particle size of pellets was influenced by the PSD of the excipients used. MCC has a narrow size distribution and lower variability in particle size when compared to other cellulose derivatives. The combination of ERL and MCC resulted in a poorly wetted mass that created excess friction in the extruder, resulting in pellets that were easily disrupted and consequently produced smaller particles with a low yield as too many fines were produced ${ }^{[28]}$. An increase in spheronization speed from 650 to $1050 \mathrm{rpm}$ resulted in a decrease in MPS from 781.8 to $575 \mu \mathrm{m}$ when the other variables were at a constant level. It has been reported that an increase in spheronizer speed results in large spherical pellets but at high speeds small spheroids are produced and at low speeds, the particles interact with each other to facilitate agglomeration of fines, resulting in an increase in MPS. The particle size and sphericity of pellets were dependent on the operating conditions and grade of MCC used ${ }^{[29]}$.

The numerical optimization tool in Design-Expert ${ }^{\circledR}$ software was used to establish optimized (OPT) values and to identify the lower (DS-LL) and upper limits (DS-UL) of the DS for each variable investigated. The

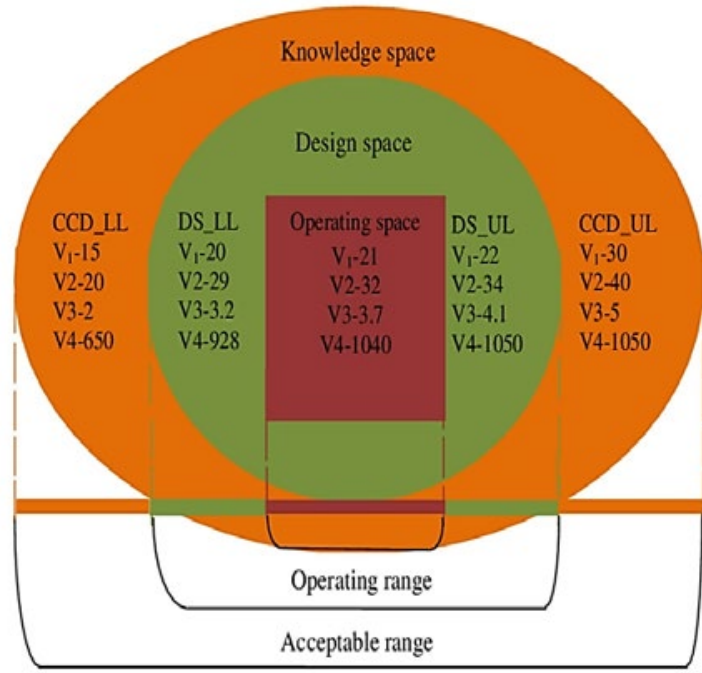

Characterization/Experimental range
Fig. 4: Schematic representation of the DS limits solutions for optimization were generated by DesignExpert ${ }^{\mathbb{B}}$ software, constituting the lower values of each variable as the lower limit for the DS and the high values as the upper limit of the DS. Numerical optimization of each variable was used to establish the DS limits within the experimental region and/or knowledge space. The operating space lies within the DS and is considered as the optimized point for this study (fig. 4). The optimized values, lower and upper limits of DS for the input variables, i.e. amount of ERL $\left(\mathrm{V}_{1}\right)$, $\% \mathrm{w} / \mathrm{w} \mathrm{MCC}\left(\mathrm{V}_{2}\right), \% \mathrm{w} / \mathrm{w} \mathrm{SSG}\left(\mathrm{V}_{3}\right)$ and spheronizer speed $\left(\mathrm{V}_{4}\right)$, with measured responses are summarized in Table 5. The results revealed that OPT, DS-LL and DS-UL formulations all exhibited a high CP loading of $>80 \% \mathrm{CP}$. The in vitro release profile for the OPT formulation is depicted in fig. 5 .

The 3 batches produced using the OPT formulation exhibited a cumulative \% CP released at $0.5 \mathrm{~h}$ that ranged between 59.60 and $76.01 \%$. The DS-LL1, DS-LL3, DS-UL1, DS-UL2 and DS-UL3 exhibited $>80 \% \mathrm{CP}$ released within $15 \mathrm{~min}$. The variable $\mathrm{CP}$ release between the 3 batches of OPT formulation was observed and a consistent release profile was achieved

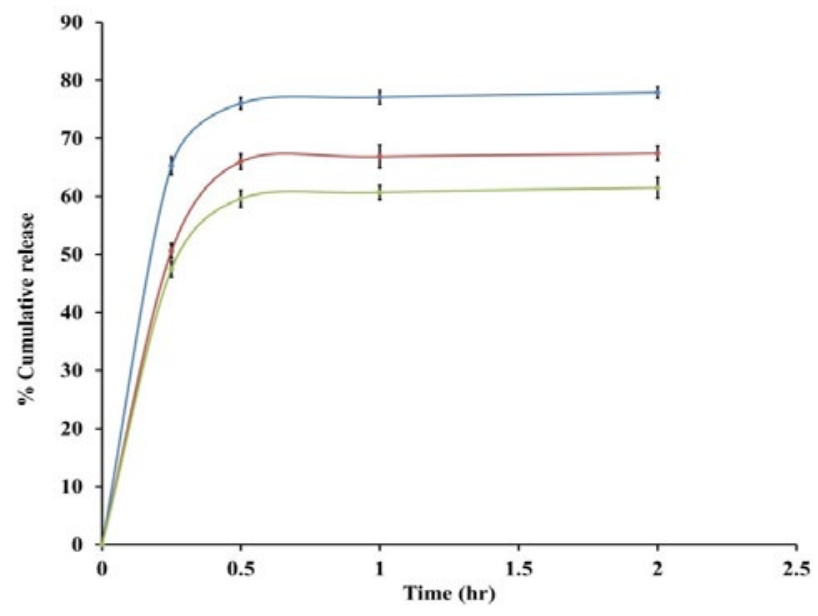

Fig. 5: Dissolution profile of CP from optimized batches $(n=3)$ (一) OPT-CP-01; (-) OPT-CP-02; (-) OPT-CP-03

TABLE 5: OPTIMIZED CP FORMULATION WITH LOWER AND UPPER LIMITS OF THE DS

\begin{tabular}{lccc}
\hline $\begin{array}{l}\text { Formulation/Process } \\
\text { variable }\end{array}$ & $\begin{array}{c}\text { Operating } \\
\text { limit }\end{array}$ & $\begin{array}{c}\text { DS lower } \\
\text { limit }\end{array}$ & $\begin{array}{c}\text { DS upper } \\
\text { limit }\end{array}$ \\
\hline $\begin{array}{l}\text { Eudragit }{ }^{\oplus} \mathrm{RL} \text { 30D }(\mathrm{ml}) \\
\left(\mathrm{V}_{1}\right)\end{array}$ & 21 & 20 & 22 \\
$\begin{array}{l}\text { Microcrystalline } \\
\text { cellulose }(\% \mathrm{w} / \mathrm{w})\left(\mathrm{V}_{2}\right)\end{array}$ & 32 & 29 & 34 \\
$\begin{array}{l}\text { Sodium starch glycolate } \\
(\% \mathrm{w} / \mathrm{w})\left(\mathrm{V}_{3}\right)\end{array}$ & 3.7 & 3.2 & 4.1 \\
$\begin{array}{l}\text { Spheronizer speed } \\
\text { (rpm) }\left(\mathrm{V}_{4}\right)\end{array}$ & 1040 & 928 & 1050 \\
\hline $\begin{array}{l}\text { The results reveal that optimized } \\
\text { formulations all exhibited a high CP loading of }>80 \% \mathrm{CP} \text {. The in vitro } \\
\text { release profile for the OPT formulation is depicted in fig. } 5\end{array}$
\end{tabular}


with DS-LL and DS-UL formulations. The OPT batches exhibited a good degree of consistency in $\% \mathrm{CP}$ content and other responses indicating good reproducibility. The changes in the drug release profile may depend on the wettability of pellets and the amount of SSG used. The moisture content of MCC and its distribution in wetted mass is a crucial factor in deciding the optimum amount of binder solution ${ }^{[30,31]}$. Higher variability in moisture content of excipient lots leads to variability of binder activity resulting in a lot-to-lot variability ${ }^{[32]}$.

A pharmaceutical product was developed using the QbD approach to establish a science-based understanding of the interaction between material attributes of raw materials and manufacturing process parameters. The use of QbD facilitated identification and assessment of the key factors that could impact product development, which are the risks related to product quality and process performance. The $\mathrm{QbD}$ framework has streamlined product development from an experience-based empirical model to a DoE approach that is based on statistical principles.

With the aid of risk assessment undertaken to identify and select material attributes and process parameters to use in appropriate ranges. A PBD experimental design was used to identify process variables or formulation composition parameters, from an extensive list of input factors that are likely to have a significant impact on the manufacture of a quality product. The use of ERL was found to be significant $(\mathrm{p}<0.05)$ for the $\%$ yield and cumulative $\% \mathrm{CP}$ released at $0.5 \mathrm{~h}$ and was considered a major factor to investigate during optimization studies. Pareto plots and ANOVA analysis data for the yield, cumulative \% $\mathrm{CP}$ released at $0.5 \mathrm{~h}$ and $\mathrm{CP}$ content confirmed that formulation parameters such as ERL, MCC and SSG content had a significant impact on the performance attributes of the $\mathrm{CP}$ pellets produced. Of all process variables, the mixer blade type and spheronizer speed had the most significant impact on yield and CP content.

A CCD approach was used to optimize the amounts of ERL, MCC and SSG and the spheronizer speed to ensure that the yield, cumulative $\% \mathrm{CP}$ released at $0.5 \mathrm{~h}, \mathrm{CP}$ content, MPS and AOR were optimized after which a DS was established for CP pellet production. Mathematical modelling and fitting of data using Design-Expert ${ }^{\circledR}$ software elucidated the relationships between formulation variables and product responses and quadratic polynomial models were defined. The optimized formulation was manufactured using 21 $\mathrm{ml} \mathrm{ERL,} 32 \% \mathrm{w} / \mathrm{w} \mathrm{MCC}$ and $3.7 \% \mathrm{w} / \mathrm{w}$ SSG at a spheronizer speed of $1040 \mathrm{rpm}$. The product DS was established using the defined lower and upper limit specifications. The \% yield, cumulative \% CP released at $0.5 \mathrm{~h}, \mathrm{CP}$ content, MPS and AOR of the optimized formulation was $65.90,54.45,90.94 \%, 880.6 \mu \mathrm{m}$ and $10.13^{\circ}$, respectively. The mechanism of release can be postulated from the release profiles and for $\mathrm{CP}$ it is likely governed through planes that are parallel to the surface of CP particle and erosion of or pore formation in pellets due to the addition of the super-disintegrant SSG. This approach to establish a DS has the potential to reduce the costs of production and enhance positive product outcomes with a minimum number of experiments.

\section{Acknowledgments:}

The authors thank the Rhodes University Research Committee (RBW) and National Research Foundation of South Africa (KV) for funding this research.

\section{Conflicts of interest:}

The authors report no conflict of interest.

\section{REFERENCES}

1. Claycamp HG. Perspective on quality risk management of pharmaceutical quality. Drug Inf J 2007;41:353-67.

2. Singh B, Raza K, Beg S. Developing "Optimized" Drug Products Employing "Designed" Experiments. Chem Ind Dig 2013;12:1-7.

3. Pravin DL, Doijad RC. Quality by design (QbD): A quality improvement per pharmaceutical development. Int J Pharm Res Biosci 2013;2:144-66.

4. Roy S. Quality by design: A holistic concept of building quality in pharmaceuticals. Int J Pharm Biomed Res 2012;3:100-8.

5. Lewis GA, Mathieu D, Phan-Tan-Luu R. Pharmaceutical experimental design. Boca Raton, FL, USA: CRC Press; 1998.

6. Chauhan K, Trivedi U, Patel KC. Statistical screening of medium components by Plackett-Burman design for lactic acid production by Lactobacillus sp. KCP01 using date juice. Bioresour Technol 2007;98:98-103.

7. Patwardhan K, Asgarzadeh F, Dassinger T, Albers J, Repka MA. A quality by design approach to understand formulation and process variability in pharmaceutical melt extrusion processes. J Pharm Pharmacol 2015;67:673-84.

8. ICH Harmonised Tripartite Guideline. Pharmaceutical development Q8 (R2). 2009. Available from: https://database. ich.org/sites/default/files/Q8_R2_Guideline.pdf.

9. Sangshetti JN, Deshpande M, Zaheer Z, Shinde DB, Arote R. Quality by design approach : regulatory need. Arab J Chem 2014;10(2):S3412-S3425.

10. Kettaneh-Wold N. Use of experimental design in the pharmaceutical industry. J Pharm Biomed Anal 1991;9:60510.

11. Cannon A, Shemeley K. Statistical evaluation of vial design features that influence sublimation rates during primary drying. Pharm Res 2004;21:536-42.

12. Veerubhotla K, Walker RB. Development and Validation of a Stability-indicating RP-HPLC Method Using Quality 
by Design for Estimating Captopril. Indian J Pharm Sci 2019;81:45-56.

13. ICH Harmonised Tripartite Guideline. Quality Risk Management Q9. 2005. Available from: https://database.ich. org/sites/default/files/Q9_Guideline.pdf.

14. O'connor RE, Schwartz JB. Spheronization II: drug release from drug-diluent mixtures. Drug Dev Ind Pharm 1985;11:1837-57.

15. Vervaet C, Baert L, Risha PA, Remon JP. The influence of the extrusion screen on pellet quality using an instrumented basket extruder. Int J Pharm 1994;107:29-39.

16. Qureshi SA, McGilveray IJ. Assessment of pharmaceutical quality of furosemide tablets from multinational markets. Drug Dev Ind Pharm 1998;24:995-1005.

17. Alvarez L, Concheiro A, Gómez-Amoza JL, Souto C, Martínez-Pacheco R. Effect of microcrystalline cellulose grade and process variables on pellets prepared by extrusionspheronization. Drug Dev Ind Pharm 2002;28:451-6.

18. Wlosnewski JC, Kumpugdee-Vollrath M, Sriamornsak P. Effect of drying technique and disintegrant on physical properties and drug release behavior of microcrystalline cellulose-based pellets prepared by extrusion/spheronization. Chem Eng Res Des 2010;88:100-8.

19. Wulff R, Leopold CS. Coatings of Eudragit ${ }^{\circledR}$ RL and L-55 blends: Investigations on the drug release mechanism. AAPS PharmSciTech 2015;17(2):493-503.

20. Bodmeier R, Guo X, Sarabia RE, Skultety PF. The influence of buffer species and strength on diltiazem $\mathrm{HCl}$ release from beads coated with the aqueous cationic polymer dispersions, Eudragit RS, RL 30D. Pharm Res 1996;13(1):52-6.

21. Kleinebudde $P$. The crystallite-gel-model for microcrystalline cellulose in wet-granulation, extrusion, and spheronization. Pharm Res 1997;14:804-9.

22. Souto C, Rodríguez A, Parajes S, Martínez-Pacheco R. A comparative study of the utility of two superdisintegrants in microcrystalline cellulose pellets prepared by extrusionspheronization. Eur. J Pharm Biopharm 2005;61:94-9.

23. Mehta KA, Kislalioglu MS, Phuapradit W, Malick AW, Shah NH. Effect of formulation and process variables on porosity parameters and release rates from a multiunit erosion matrix of a poorly soluble drug. J Control Release 2000;63:201-11.

24. Rahman NU, Yuen KH. Eudragit NE40-Drug Mixed Coating System for Controlling Drug Release of Core Pellets. Drug Dev Ind Pharm 2005;31:339-47.

25. Wildman RD, Blackburn S. Breakdown of agglomerates in ideal pastes during extrusion. J Mater Sci 1998;33:5119-24.

26. Zhang L, Jiang P, Liu J. Novel Sustained-Release of Propafenone through Pellets: Preparation and in Vitro/in Vivo Evaluation. Int J Mol Sci 2014;15:15503-11.

27. Elbers JAC, Bakkenes HW, Fokkens JG. Effect of amount and composition of granulation liquid on mixing, extrusion and spheronization. Drug Dev Ind Pharm 1992;18:501-17.

28. Tiwari R, Agarwal SK, Tiwari S. Formulation and multivariate optimization of microcrystalline cellulose pellets of highly water soluble drug. Int J Drug Deliv 2013;5:206-13.

29. Wan LSC, Heng PWS, Liew CV. Spheronization conditions on spheroid shape and size. Int J Pharm 1993;96:59-65.

30. Dukić-Ott A, Thommes M, Remon JP, Kleinebudde P, Vervaet C. Production of pellets via extrusion-spheronisation without the incorporation of microcrystalline cellulose: A critical review. Eur J Pharm Biopharm 2009;71:38-46.

31. Sousa JJ, Sousa A, Podczeck F, Newton JM. Factors influencing the physical characteristics of pellets obtained by extrusionspheronization. Int J Pharm 2002;232:91-106.

32. Chatlapalli R, Rohera BD. Physical characterization of HPMC and HEC and investigation of their use as pelletization aids. Int J Pharm 1998;161:179-93. 